\title{
Humic acid fouling mitigation by ultrasonic irradiation in membrane distillation process
}

\author{
Deyin Hou ${ }^{\mathrm{a}, \mathrm{b}, *}$, Lijuan Zhang $^{\mathrm{c}}$, Zhangxin Wang ${ }^{\mathrm{d}}$, Hua Fan ${ }^{\mathrm{e}}$, Jun Wang ${ }^{\mathrm{a}, \mathrm{b}, *}$, Hongjing Huang ${ }^{\mathrm{e}}$ \\ ${ }^{a}$ Key Laboratory of Drinking Water Science and Technology, Research Center for Eco-Environmental Sciences, Chinese Academy of Sciences, Beijing 100085, PR China \\ ${ }^{\mathrm{b}}$ Beijing Key Laboratory of Industrial Wastewater Treatment and Reuse, Research Center for Eco-Environmental Sciences, Chinese Academy of Sciences, Beijing 100085, PR China \\ ' School of Environmental and Chemical Engineering, Nanchang Hangkong University, Jiangxi 330063, PR China \\ ${ }^{\mathrm{d}}$ Department of Civil and Environmental Engineering, Vanderbilt University, PMB 51831, 2301 Vanderbilt Place, Nashville, TN 37235-1831, United States \\ e School of Environmental and Chemical Engineering, Nanchang University, Jiangxi 330031, PR China
}

\section{A R T I C L E I N F O}

\section{Article history:}

Received 26 May 2015

Received in revised form 29 September 2015

Accepted 29 September 2015

Available online 30 September 2015

\section{Keywords:}

Membrane distillation

Membrane fouling

Humic acid

Ultrasonic irradiation

\begin{abstract}
A B S T R A C T
A novel ultrasonic assisted direct contact membrane distillation hybrid process was designed and the effect of ultrasonic irradiation on humic acid (HA) fouling mitigation during membrane distillation process was investigated. Although permeate flux declines were negligible (less than 5\%) for the ranges of $\mathrm{HA}$ concentration studied, ultrasonic irradiation could enhance the permeate flux more than $30 \%$ without destroying HA rejection. The higher the concentration factor was, the larger the ultrasonic enhancement of permeate flux could be obtained. Severe permeate flux decline can be found when $\mathrm{CaCl}_{2}$ was added into the HA solution. The presence of $\mathrm{Ca}^{2+}$ would aggravate HA organic fouling phenomenon and resulted in a thick and dense HA fouling layer on membrane surface. The HA fouling increased heat transfer resistance and reduced the pores available for vapor transfer, both the permeate flux and thermal efficiency of the PTFE membrane declined. Under ultrasonic irradiation, ultrasonic wave refreshed the liquidmembrane interface continuously and alleviated the deposition of HA aggregates. Therefore, although there were still some HA fouling scattered on membrane surface, most of the membrane pores could be kept open and clean, the relative permeate flux can maintain above $94 \%$ and was hardly affected by concentration factor increasing.
\end{abstract}

(c) 2015 Elsevier B.V. All rights reserved.

\section{Introduction}

Membrane distillation (MD) is a promising thermally driven desalination technology and usually used a hydrophobic membrane as separation media [1]. Compared with other desalination processes such as nanofiltration (NF), reverse osmosis (RO) and conventional evaporation, MD has several unique advantages such as: (1) lower operating temperature and vapor space required than conventional distillation, (2) lower operating pressure than RO, (3) theoretically $100 \%$ salt rejection, (4) unlimited by high osmotic pressure, and (5) lower energy consumption than multistage vacuum evaporation [2-5].

Although there have been extensive studies on the application of MD for water desalination, removal of organic matters in drinking water production, treatment of water and wastewater, recovery of valuable components, and treatment of radioactive wastes

* Corresponding authors at: Key Laboratory of Drinking Water Science and Technology, Research Center for Eco-Environmental Sciences, Chinese Academy of Sciences, Beijing 100085, PR China.

E-mail addresses: dyhou@rcees.ac.cn (D. Hou), junwang@rcees.ac.cn (J. Wang).
[6-11], the industrial implementation of MD is not yet feasible and significant advancements are still needed to reach the theoretical cost competitiveness and develop market share growth [12]. Like all other membrane processes, fouling in MD is of particular importance, as fouling can alter membrane surface properties, change membrane pore structure, potentially lead to wetting of membrane pores and ultimately cause a decline in membrane permeability $[13,14]$. In recent years, a number of studies have investigated the effect of fouling on the overall MD process utilizing different types of membranes such as flat-sheet and hollow fibers, as well as using different modules [15]. However, the majority of works focus on the negative effects and mitigation strategies of inorganic membrane scaling such as $\mathrm{CaSO}_{4}, \mathrm{CaCO}_{3}$ and $\mathrm{SiO}_{2}$ [16-18]. As far as we know, there are limited studies dedicated to organic fouling in the MD process.

It has been acknowledged that natural organic matter (NOM) is one of the primary causes for the membrane permeability decline due to organic fouling [19]. It was reported that humic substances and low molecular weight organics are the main constituents of NOM present in natural water sources such as surface water, 
ground water and seawater [20]. Furthermore, humic acid (HA) has been identified as the principal NOM foulant in membrane processes [21]. With regards to the MD process, it is deemed necessary to pay more attention on HA fouling because it has been demonstrated that HA is adsorbed more favorably onto hydrophobic membrane surface [22]. Khayet and Mengual [23] investigated the treatment of HA solutions through direct contact membrane distillation (DCMD), it was found that the extent of HA fouling was affected by HA concentration, feed $\mathrm{pH}$ and transmembrane temperature difference. Srisurichan et al. [24] studied the effects of ionic strength, divalent ion and feed $\mathrm{pH}$ on $\mathrm{HA}$ fouling, flux declines were less than $6 \%$ for the ranges of HA concentration, ionic strength, and $\mathrm{pH}$ studied. The presence of calcium ions had a marked effect on HA fouling, $\mathrm{Ca}^{2+}$ formed complexes with HA and resulted in coagulation on the polyvinylidene fluoride (PVDF) membrane surface. Naidu et al. [25] reported that the HA fouling in MD was influenced by temperature, salinity $(\mathrm{NaCl})$ and inorganic scalant $\left(\mathrm{CaSO}_{4}\right)$, and $\mathrm{HA}$ can penetrate through the hydrophobic membrane and present in permeate. Meng et al. [26] also found that HA penetrated through both virgin and superhydrophobic PVDF membranes even without the occurrence of partial pore wetting, and they proposed adsorption-desorption foulant migration mechanism through the membrane to explain this experimental phenomena.

Fouling in MD is generally less serious than that in pressuredriven membrane processes, however, reduction of fouling by NOM in MD process, such as HA, is still one of the major challenges. Srisurichan et al. [24] found that pure water rinsing was not sufficient to recover the initial permeate flux, while HA fouling was easily removed with a $0.1 \mathrm{M} \mathrm{NaOH}$ solution and $100 \%$ flux recovery was attained. It is also reported that thermal heating in MD may influence the characteristics of $\mathrm{HA}$, and alternating temperature changes can clean HA fouling in some extent [27]. Nevertheless, it is worth highlighting that the HA fouling control methods used in pressure-driven membrane processes may be full of important reference value. For example, Hong and Elimelech [28] added chelating agent (EDTA) into feed water in NF membrane process, reduced HA fouling significantly and also improved the cleaning efficiency dramatically. Because the presence of divalent cation has a marked effect on HA fouling, selective removal of divalent cation via pretreatment was suggested to reduce the adverse effect of divalent ions [29]. In addition, antiscalants were widely used to control inorganic scales such as $\mathrm{CaCO}_{3}$ and $\mathrm{CaSO}_{4}$ formed on NF or RO membrane surfaces, Yang et al. [30] tried to use a benign antiscalant polyaspartic acid to mitigate HA fouling on RO membrane. $\mathrm{HA}$ fouling decreased with $\mathrm{Ca}^{2+}$ concentration increasing in the presence of polyaspartic acid, and it was a feasible approach for HA fouling control by dosing antiscalant.

Ultrasonic wave is referred to the acoustic wave with the frequency between $20 \mathrm{kHz}$ and $10 \mathrm{MHz}$. Several concomitant effects, such as mechanics, thermotics and cavatition effect, during the propagation of ultrasonic wave in various media, have been recognized to be beneficial to many physical and chemical processes [31]. For membrane separation processes, the ultrasonic technique is used mainly in membrane fouling monitoring, membrane cleaning and membrane flux enhancement [32-36]. Li et al. [37-39] applied ultrasonic technique as a non-destructive, real-time, in situ measuring technique for direct monitoring of membrane fouling and cleaning during ultrafiltration (UF) and RO, and found that the ultrasonic technique was a useful technique for the nondestructive investigation of fouling and cleaning in membrane applications. Kobayashi et al. [40-44] introduced ultrasonic technique to create novel anti-fouling membrane processes for membrane water treatments, it was reported that ultrasonic irradiation during membrane filtration was very effective in removing foulants from membranes. Massive evidences exist that the ultrasonic effect is useful for water cleaning of fouled membrane, the ultrasonic cleaning presents advantages and is an effective method compared with other typical cleaning methods using physical and chemical methods [45-47].

Although the ultrasonic irradiation has been successfully applied to enhance the performance of pressure-driven membrane separation process such as microfiltration (MF), UF, NF and RO, relatively few studies have been carried out with the use of ultrasonic to mitigate HA fouling in MD process. The objective of this paper is to introduce ultrasonic irradiation into DCMD process to develop a novel ultrasonic assisted direct contact membrane distillation (USDCMD) hybrid process and to investigate the influence of ultrasonic irradiation on HA fouling mitigation. Compared with traditional physical and chemical methods for membrane fouling control, ultrasonic irradiation is expected to be a real-time, in situ membrane fouling mitigation technique and can also ensure MD system continuous operation without chemicals addition and membrane drying.

\section{Experimental}

\subsection{Materials and membrane module}

The polytetrafluoroethylene (PTFE) hydrophobic hollow fiber membrane with a mean pore diameter of $0.26 \mu \mathrm{m}$, supplied by DD Water Group Co., Ltd. (China), was chosen to fabricate membrane modules. The hollow fibers in the number of 40 pieces were assembled into a polyester tube (diameter $d_{\text {in }} / d_{\text {out }}=15 / 20 \mathrm{~mm} / \mathrm{mm}$ ) with two UPVC T-tubes and two ends of the bundle of fibers were sealed with solidified epoxy resin to compose a membrane module. The effective membrane length was $100 \mathrm{~mm}$ for each membrane module. The characteristics of the membrane and membrane modules are presented in Table 1.

\subsection{USDCMD setup}

The USDCMD experimental setup is schematically shown in Fig. 1 . The hot feed stirred continually by a magnetic stirrer flowed through the shell side of the fibers, and the cold distillate flowed through the lumen side. The initial volumes of the feed and the distillate were $4.0 \mathrm{~L}$ and $0.25 \mathrm{~L}$, respectively. Both solutions were circulated in the membrane module with the help of two magnetic pumps (MP-15RN, Shanghai Seisun Pumps, China). The feed and the distillate flowed co-currently through the module, and the circulation feed rate $\left(V_{f}\right)$ was $0.25 \mathrm{~m} / \mathrm{s}$, while the cold side $\left(V_{p}\right)$ being $1.0 \mathrm{~m} / \mathrm{s}$. The feed temperature $\left(T_{f \text {-inlet }}\right)$ was fixed at $53^{\circ} \mathrm{C}$ by a Pt-100 sensor and a heater connected to an external thermostat (XMTD-2202, Yongshang Instruments, China). The distillate temperature $\left(T_{p \text {-inlet }}\right)$ kept at $20^{\circ} \mathrm{C}$ by a spiral glass heat exchanger immersed in the constant temperature trough of the cooler (SDC-6, Nanjing Xinchen Biotechnology, China). The temperature of both fluids was monitored at the inlet and outlet of the membrane module using four Pt-100 thermoresistances connected to a digital

Table 1

The characteristics of the membrane material and the membrane module.

\begin{tabular}{ll}
\hline Membrane and module & Properties \\
\hline Membrane material & PTFE \\
Mean pore diameter $(\mu \mathrm{m})$ & 0.26 \\
Porosity (\%) & 45.07 \\
Inner diameter of hollow fiber $(\mathrm{mm})$ & 0.80 \\
Membrane thickness $(\mathrm{mm})$ & 0.39 \\
Number of hollow fibers & 40 \\
Effective membrane length $(\mathrm{mm})$ & 100 \\
Effective membrane area $\left(\mathrm{cm}^{2}\right)$ & 198.4
\end{tabular}




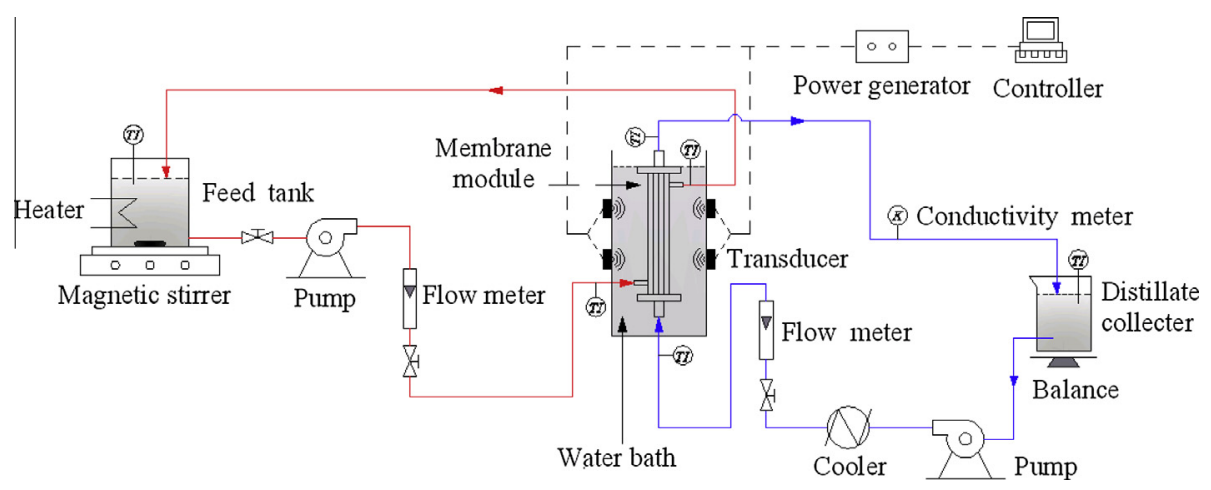

Fig. 1. Schematic diagram of USDCMD system.

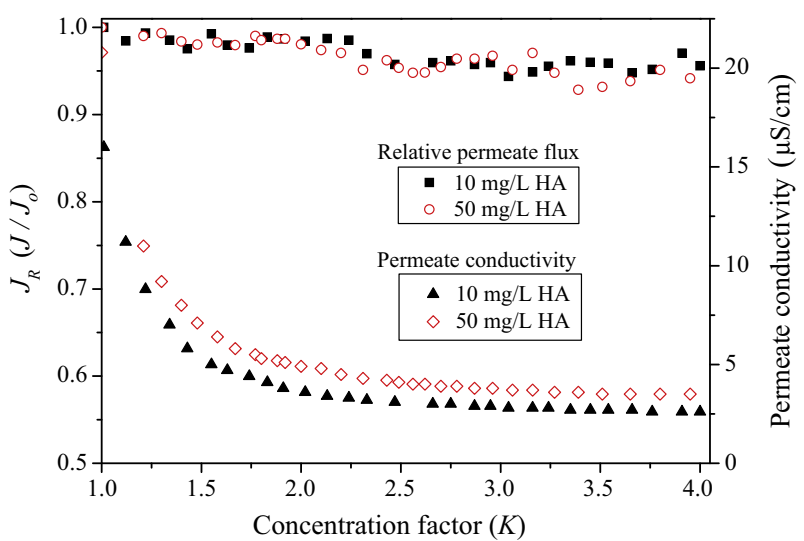

Fig. 2. Effect of HA concentration on the process of DCMD concentration of HA solution.

meter (Digit RTD, model XMT-808, Yuyao Changjiang Temperature Meter Instruments, China) with an accuracy of $\pm 0.1^{\circ} \mathrm{C}$. An electric conductivity monitor (CM-230A, Shijiazhuang Create Instrumentation Technologies, China) was used to monitor the distillate water quality.

In order to investigate the influence of ultrasonic irradiation on HA fouling mitigation, the membrane module was immersed vertically in a water bath $\left(15 \times 15 \times 42 \mathrm{~cm}^{3}\right)$, transducers were adhered to the four outside surfaces of the water bath stainless steel shell. The ultrasonic bath was capable of generating ultrasonic with a frequency of $20 \mathrm{kHz}$ and an acoustic power of $260 \mathrm{~W}$. The ultrasonic irradiation device was supplied by Quanyi Electronic Equipment Co., Ltd. (Baoding, China).

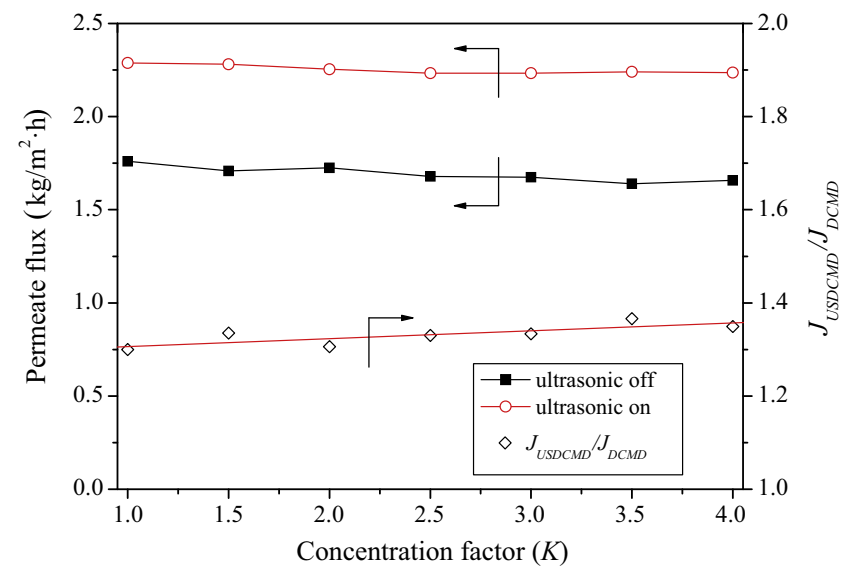

Fig. 4. Effect of ultrasound irradiation on the permeate flux during HA solution concentration process.

\subsection{Experimental}

Humic acid was supplied by Sinopharm Chemical Reagent Co., Ltd. (China). Feed solutions were prepared by dissolving a preweighed quantity of HA powder in deionized water obtained from the Milli-Q system (Millipore, USA), followed by filtration through a $0.45 \mu \mathrm{m}$ filter to exclude initial deposition of bulk suspended solids on the membrane. The solution $\mathrm{pH}$ was adjusted to 7.0 by addition of small quantities of $0.1 \mathrm{M} \mathrm{NaOH}$ as needed before MD experiment starting. The HA concentration of the permeate were evaluated by measuring the absorbance using a Hach DR-5000 UV-Vis spectrophotometer (Hach, USA) at $207 \mathrm{~nm}$. This wave-

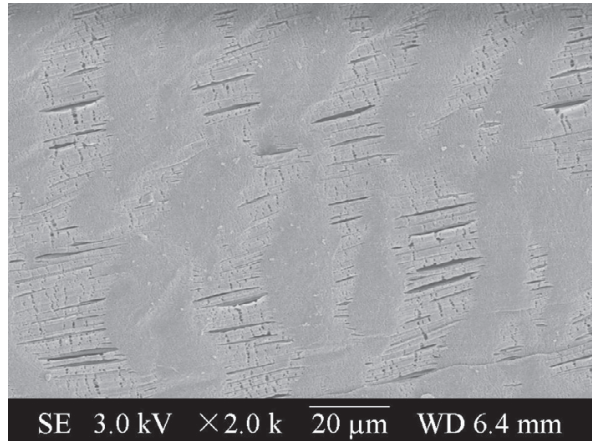

(a)

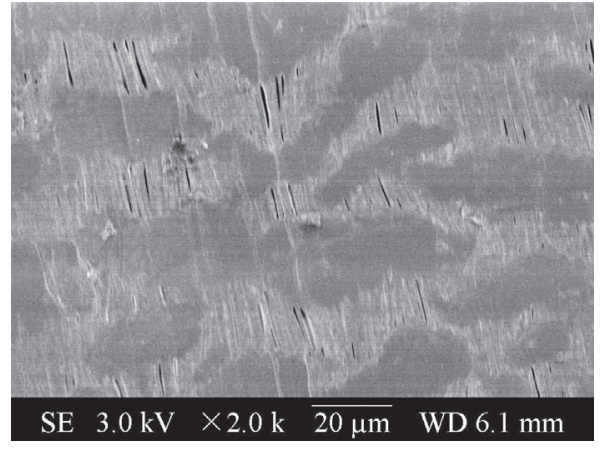

(b)

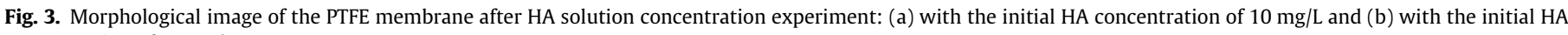
concentration of $50 \mathrm{mg} / \mathrm{L}$. 


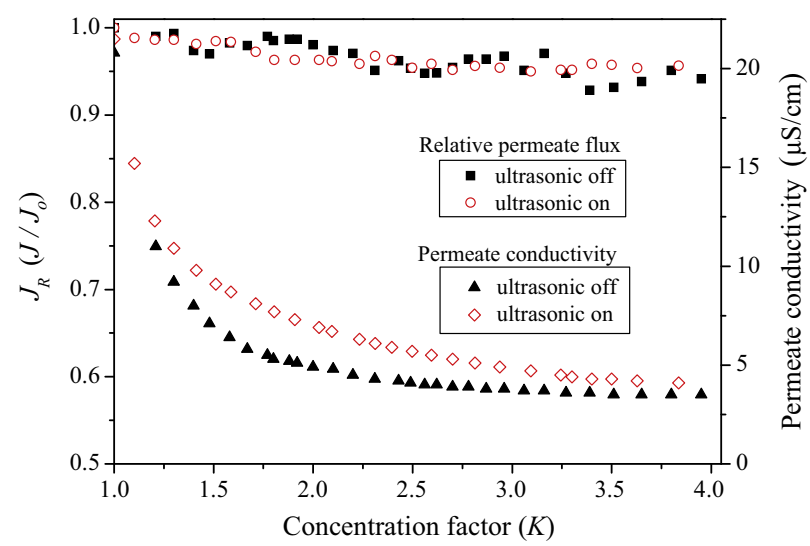

Fig. 5. Effect of ultrasound irradiation on the process of DCMD concentration of HA solution.

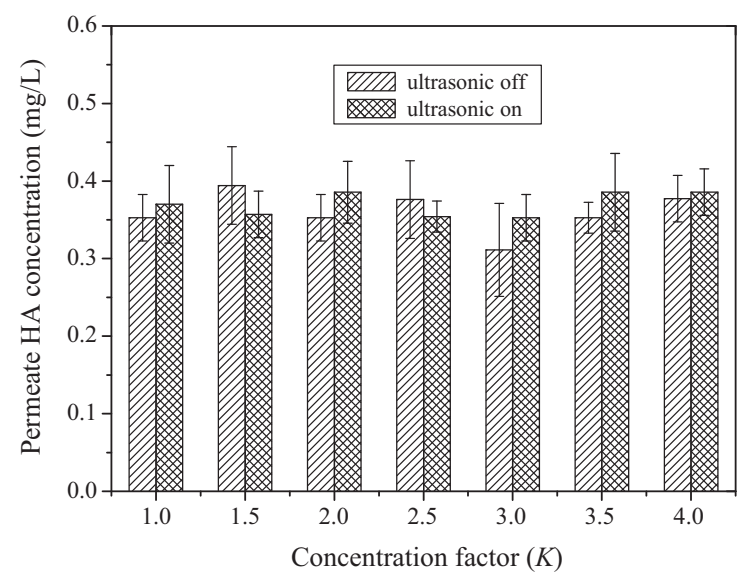

Fig. 6. Effect of ultrasound irradiation on permeate HA concentration.

length gave a maximum absorbance over the HA concentration range in the obtained permeate.

During MD process, all the feed solutions were no make-up water added into the feed tank, which meant that the feed was gradually concentrated. The concentration factor $K$ can be calculated by the following equation:

$K=\frac{Q_{0}}{Q_{0}-Q_{p}}$

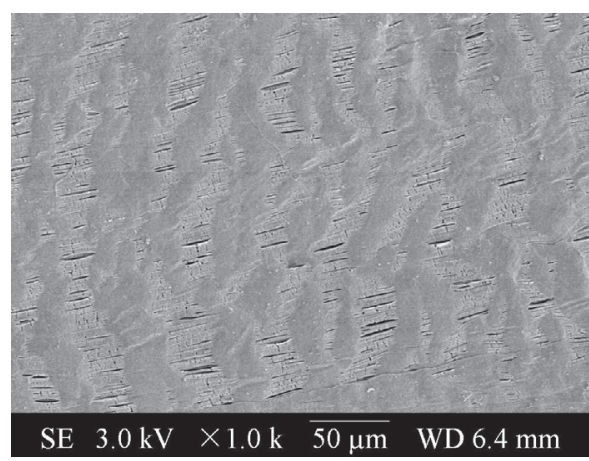

(a) where $Q_{o}$ is the initial quantity of feed $(\mathrm{kg}), Q_{p}$ is the cumulative permeate production $(\mathrm{kg})$. The permeate flux $J$ was calculated by the following equation:

$J=\frac{\Delta W}{A \Delta t}$

where $J$ is the permeate flux $\left(\mathrm{kg} / \mathrm{m}^{2} \mathrm{~h}\right), \Delta W$ is the quantity of distillate $(\mathrm{kg}), A$ is the effective area of flat-sheet membrane $\left(\mathrm{m}^{2}\right)$ and $\Delta t$ is the sampling time (h). The relative permeate flux $J_{R}$ was used to describe the change of membrane permeability with the concentration factor increase:

$J_{R}=\frac{J}{J_{o}}$

where $J_{o}$ is the initial permeate flux $\left(\mathrm{kg} / \mathrm{m}^{2} \mathrm{~h}\right)$. When the concentration factor reached 4.0, the MD process was stopped, and a new membrane module was used for each experiment in this study. At the completion of each experiment, the membrane was removed from the membrane module for further analysis and excess liquid on the membrane surface was allowed to drain off by gently tilting the hollow fiber.

\subsection{Membrane surface analysis}

The HA fouling on the membrane surface was observed by using a HITACHI S-3000N scanning electron microscope (SEM) (Hitachi Ltd., Japan). The fouled membranes were dried in a desiccator, and sputtered with platinum using a HITACHI E-1010 Ion Sputtering device for SEM observation. Elemental analysis of the fouled membrane surface was accomplished using energy dispersive X-ray spectroscopy (EDS) detector. The fouled membrane samples were handled gently and without any excessive forces to ensure that the fouling remained intact.

\section{Results and discussions}

\subsection{The effect of humic acid concentration}

The solutions containing $10 \mathrm{mg} / \mathrm{L}$ and $50 \mathrm{mg} / \mathrm{L}$ HA were tested for concentration by DCMD, respectively. The permeate flux as a function of concentration factor is illustrated in Fig. 2.

It was found that the HA concentration had little effect on the permeate flux and the organic foulant HA did not cause notable flux decline with the concentration factor increase. For different HA concentration, the initial permeate fluxes of the PTFE hollow fiber membranes were almost the same and about $1.76 \mathrm{~kg} / \mathrm{m}^{2} \mathrm{~h}$. With the concentration factor increasing, the relative permeate

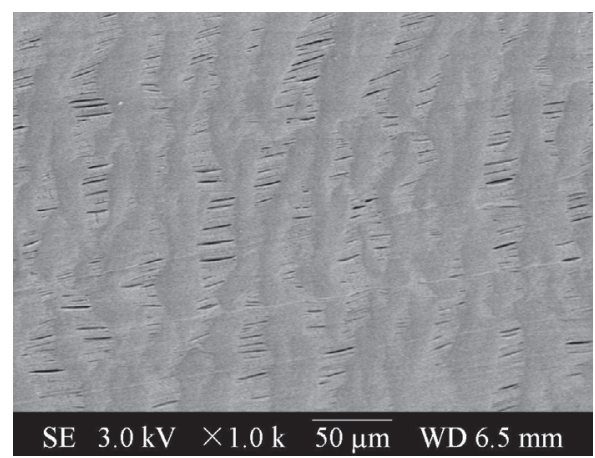

(b)

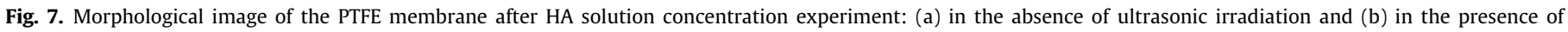
ultrasonic irradiation. 
fluxes can still keep constant during the DCMD concentration operation. When the concentration factor reached 4.0 , the permeate flux declined less than $5 \%$ compared with the initial permeate flux for the feed with different HA content.

The SEM micrographs of the PTFE membranes used in different feed concentration process are presented in Fig. 3. It can be found that the membrane surface still kept clean when the experiments ending, and these results indicated negligible HA fouling, even the HA concentration was as high as $50 \mathrm{mg} / \mathrm{L}$, which was consistent with the findings of Srisurichan [24] and Khayet [48]. On the contrary, in the pressure-driven membrane separation process such as MF, UF and NF of the solutions with lower HA concentration [21],

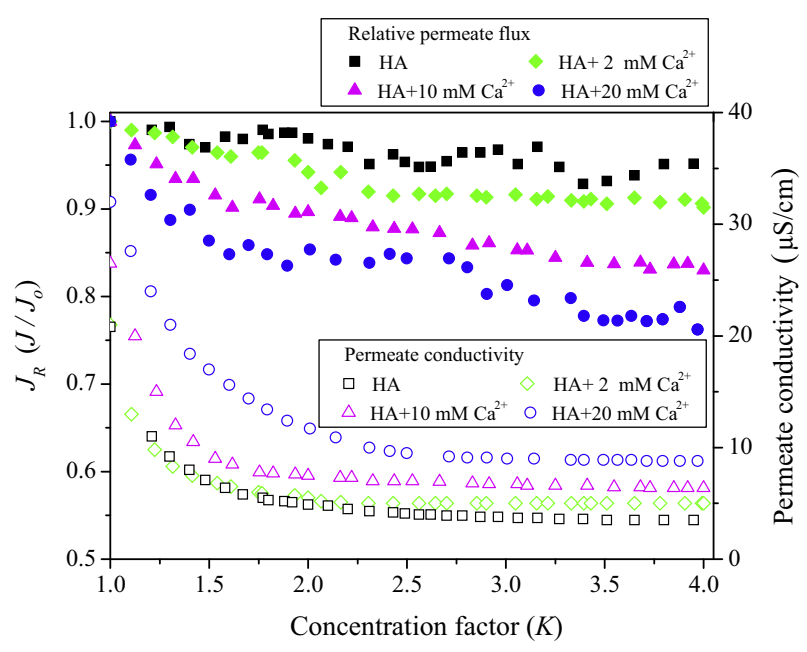

Fig. 8. Effect of calcium ion on the process of DCMD concentration of HA solution. the permeate flux would decline significantly in a very short time. Being different from pressure-driven membrane process, MD is a thermally driven process and there is a thermally driven vapor transport through non-wetted porous hydrophobic membrane where the driving force is the partial vapor pressure difference across the two sides of membrane pores. In MD process, the feed solution to be treated cannot permeate into the membrane pores. Therefore, the HA would not deposit in membrane pores. Furthermore, due to the lower operating pressure of the process, even there were HA aggregates formed on the membrane surface, the deposition would be less compact and be easily flushed off the membrane surface, slightly affect the transport resistance.

\subsection{Ultrasonic irradiation effect on DCMD of humic acid solution}

The effect of ultrasonic irradiation on absolute permeate flux and relative permeate flux are shown in Figs. 4 and 5, respectively. It can be seen that ultrasonic irradiation really increased the permeate flux. Although the permeate flux seemed to be hardly affected by the concentration factor increasing both in the presence and absence of ultrasonic irradiation, the slight rise of the ratio of membrane permeate flux with and without ultrasonic irradiation as shown in Fig. 4 indicated that the higher the concentration factor was, the more obvious the ultrasonic enhancement of permeate flux could be obtained. When the concentration factor varied from 1.0 to 4.0 , the ratio of permeate flux with and without ultrasonic irradiation enhanced from 1.30 to 1.37 . With the concentration factor increasing, both the feed viscosity and the boundary layer thickness increased, which would aggravate concentration polarization on the membrane surface and cause the permeate flux decline in some extent. Ultrasonic irradiation can bring mechanical and thermal effects and generate powerful shock wave and microstreaming with high speed, which were ben-

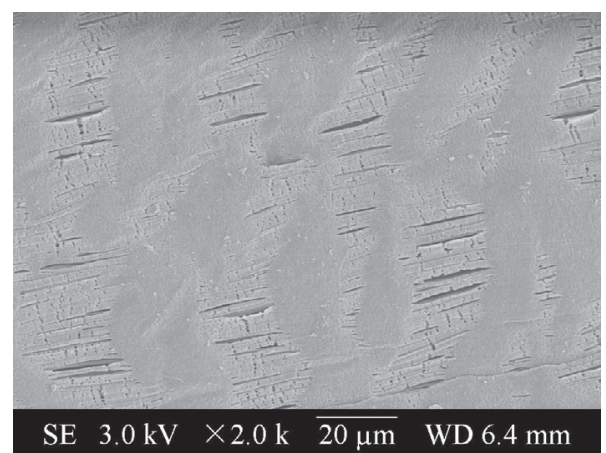

(a)

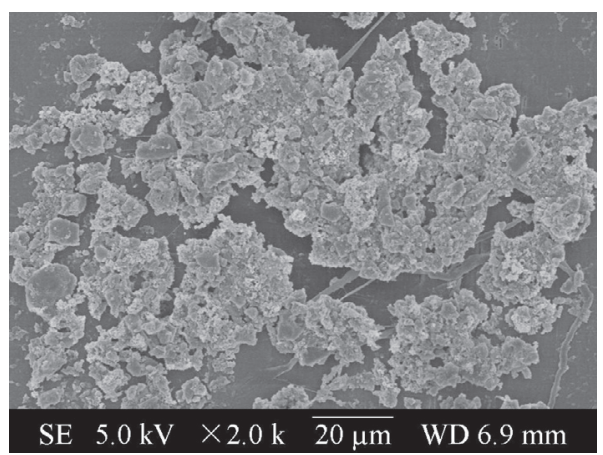

(c)

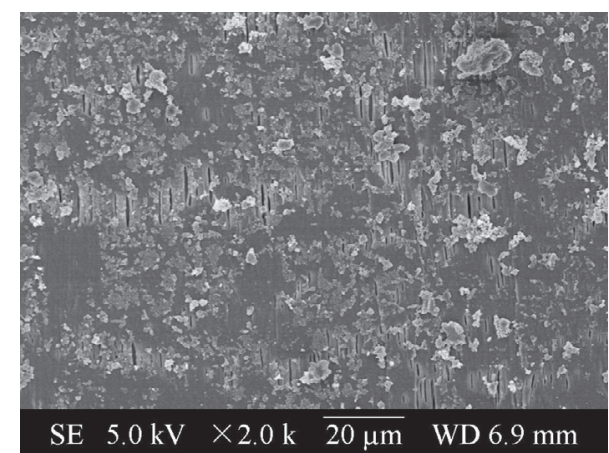

(b)

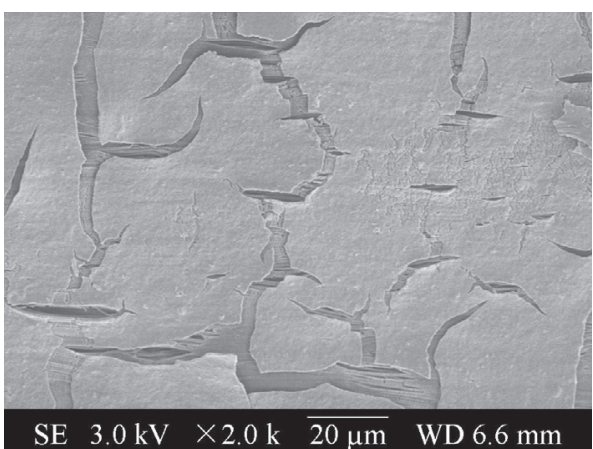

(d)

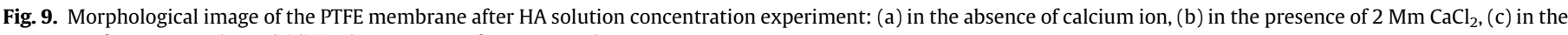
presence of $10 \mathrm{Mm} \mathrm{CaCl}_{2}$, and (d) in the presence of $20 \mathrm{Mm} \mathrm{CaCl}_{2}$. 
eficial to reduce the boundary layer, intensified eddy diffusion and relieve the negative effect of concentration factor increase on the mass transfer of DCMD process.

The ultrasonic irradiation can enhance permeate flux, however, it should be certified whether the PTFE hollow fibers can maintain excellent HA rejection under ultrasonic irradiation. In Fig. 5, it can be seen that the permeate conductivity declined with the elapse of operation time in the presence or absence of ultrasonic irradiation, which meant that the permeate quality was even better than the deionized water. The PTFE membranes kept good HA rejection and all permeate $\mathrm{HA}$ concentration were below $0.40 \mathrm{mg} / \mathrm{L}$ with and without ultrasonic irradiation as shown in Fig. 6. Furthermore, as can be found from Fig. 7, there was no obvious difference between the surface SEM images of the PTFE membranes before and after ultrasound irradiation. For the PTFE hollow fiber membrane, both the performance stability and membrane morphology were hardly influenced by ultrasonic irradiation, which indicated that the PTFE membrane was suitable to be utilized in ultrasonic assisted direct contact membrane distillation hybrid process to mitigate HA fouling.

\subsection{The effect of calcium ion}

Calcium ion is a major cation in natural and waste waters, thus, the effect of calcium ion was studied in the present paper. The initial feed solution contained $50 \mathrm{mg} / \mathrm{L} \mathrm{HA}$ and the concentration of
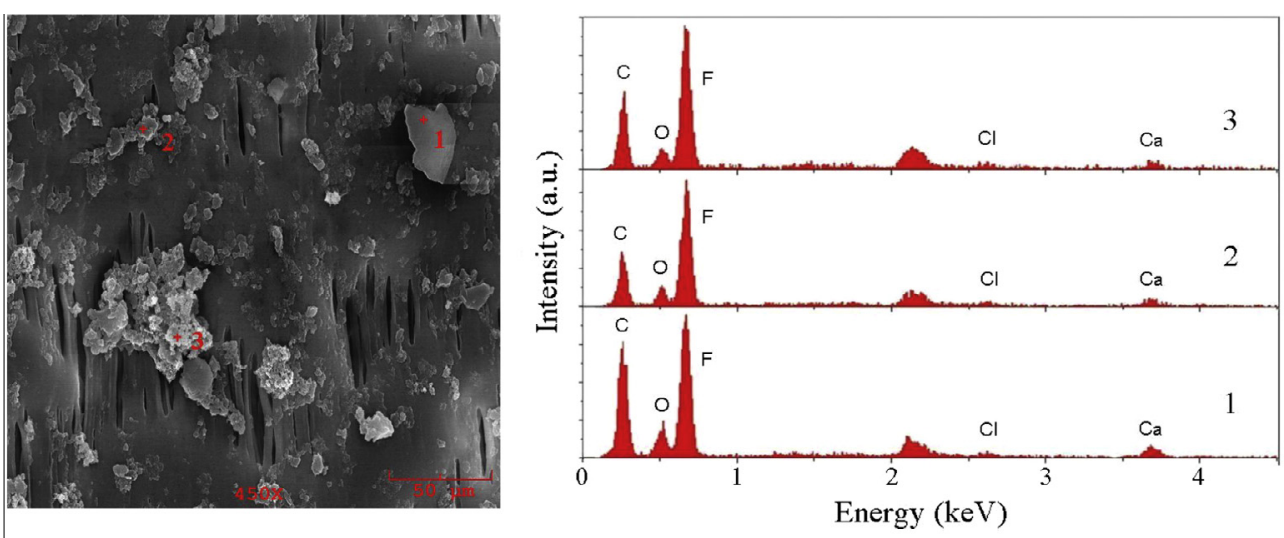

(a)
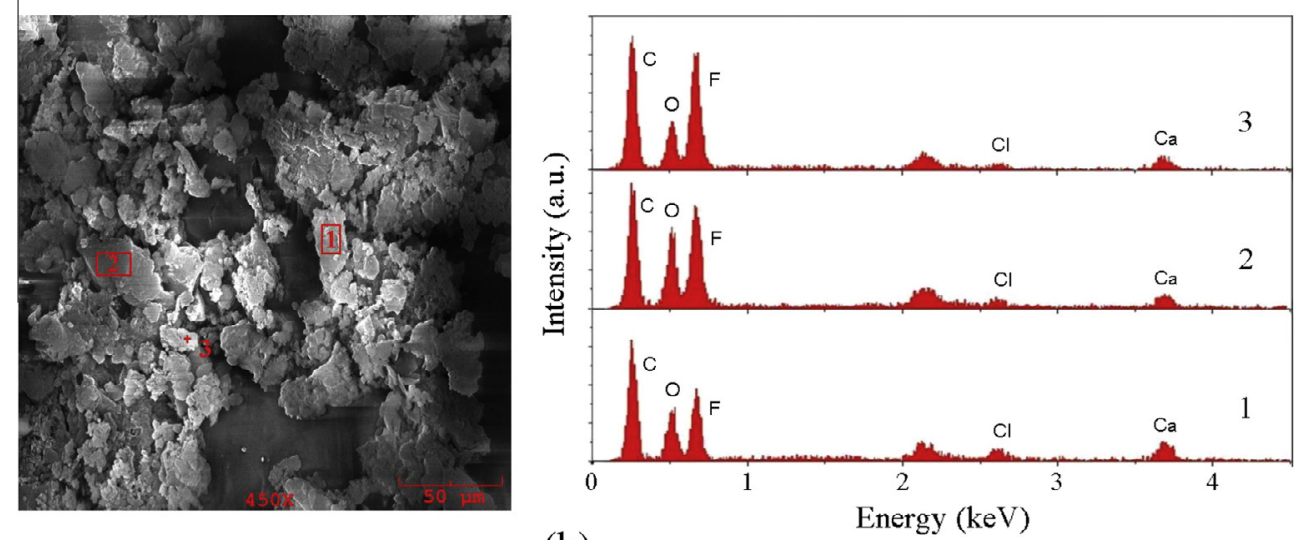

(b)
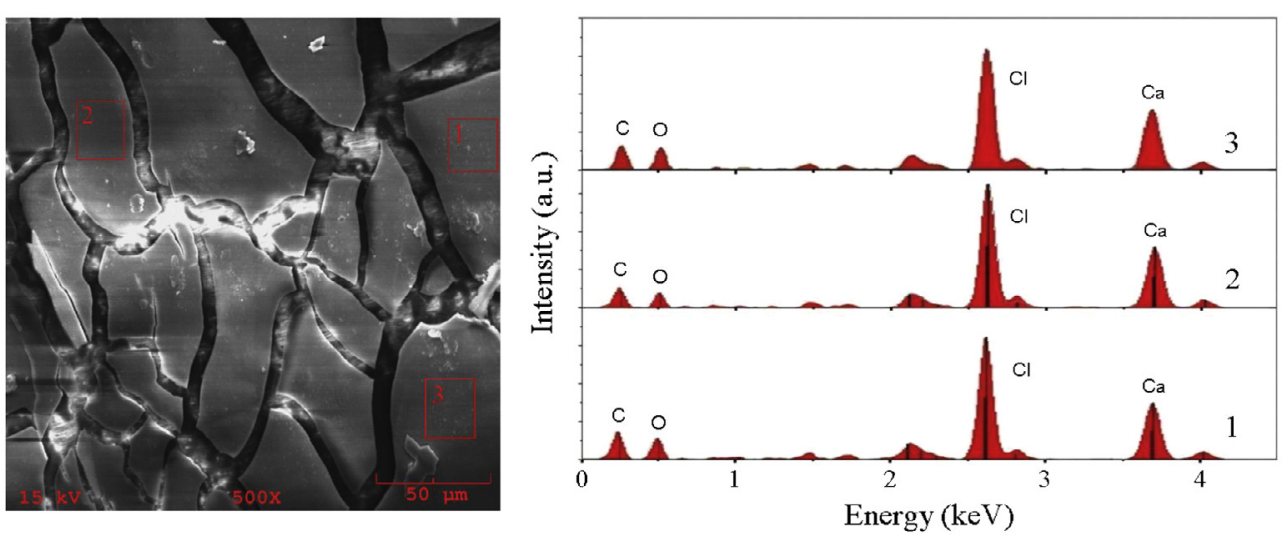

(c)

Fig. 10. SEM-EDS analysis of the fouling scattered on membrane surface: (a) in the presence of $2 \mathrm{Mm} \mathrm{CaCl}_{2}$, (b) in the presence of $10 \mathrm{Mm} \mathrm{CaCl}_{2}$, and (c) in the presence of $20 \mathrm{Mm} \mathrm{CaCl}_{2}$. 
the salt $\mathrm{CaCl}_{2}$ in feed solution was in the range of $0-20 \mathrm{mM}$. The curves for relative permeate flux with concentration factor under various conditions are shown in Fig. 8. It is clearly different from the DCMD of pure HA, the results reveal the flux decline when the salt $\mathrm{CaCl}_{2}$ was added into the HA solution. As can be seen from Fig. 8 , the relative permeate flux $J / J_{o}$ decline at the end of experiment increased from $4.8 \%$ to $23.7 \%$ as $\mathrm{Ca}^{2+}$ concentration increased from 0 to $20 \mathrm{mM}$, and the decline of relative permeate flux increased with increasing calcium ion concentration.

According to HSAB theory, the divalent cation $\mathrm{Ca}^{2+}$ is a hard acid, which easily interacts with hard bases such as $-\mathrm{COO}^{-}$. Since $\mathrm{HA}$ contains negatively charged carboxyl groups, $\mathrm{Ca}^{2+}$ can act like a binding agent of two carboxyl functional groups and form complexes, which cause the humic acids aggregate. On the other side, the addition of cation $\mathrm{Ca}^{2+}$ also reduced electrostatic repulsion between HA molecules and that between HA and PTFE hydrophobic membrane surface. The presence of divalent cation $\mathrm{Ca}^{2+}$ would aggravate HA organic fouling phenomenon via charge neutralization, complexation and formation of calcium bridges. The SEM micrographs shown in Fig. 9 obviously confirmed that the presence of divalent cation $\mathrm{Ca}^{2+}$ in feed solution aggravated HA organic fouling. With the increase of calcium ion concentration, the membrane fouling became worse and worse. It can be found that there were some foulants scattered on membrane surface when $2 \mathrm{mM} \mathrm{CaCl}$ was added into the HA solution, then the membrane foulants formed loose aggregates with $10 \mathrm{mM} \mathrm{CaCl}_{2}$ addition, the PTFE membrane was finally covered by a dense fouling layer in the presence of $20 \mathrm{mM} \mathrm{CaCl}_{2}$. Certainly, the SEM-EDS analysis presented in Fig. 10 revealed that the deposit on the membrane surface was the complex formed by HA and divalent cation $\mathrm{Ca}^{2+}$, and the calcium content in membrane foulants increased with the salt $\mathrm{CaCl}_{2}$ concentration increasing.

It is well known that membrane distillation is a simultaneous heat and mass transfer process. The deterioration of permeate flux due to HA fouling may be attributed to two factors, the reduction of surface area available for vaporization as the fouling blocked the pore entrances, and the fouling layer may decrease the heat transfer driving force. Even though there has been no report on the heat transfer resistance of the fouling layer, it is expected that such a layer will reduce the temperature polarization coefficient, and the temperature polarization coefficient reflects the heat transfer efficiency of the process in some extent.

During MD process, heat transport can be divided into the latent heat due to water vaporization and the heat conduction across the membrane. The heat transfer from the hot feed to the cold stream induced temperature decrease from the inlet of the shell side to the outlet and vice versa for the lumen side. Thermal efficiency (evaporation efficiency, $E E$ ) was defined as the ratio

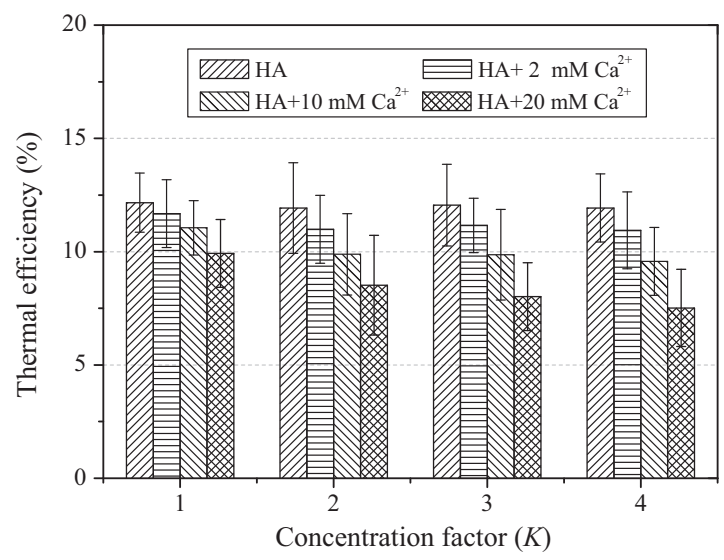

Fig. 11. Effect of calcium ion on thermal efficiency of the DCMD process. between the heat which contributed to evaporation and the total heat exchanged between two streams. Because distillate water flows through the fiber lumen side, there is no other heat transfer except for heat from the fiber shell side. The total heat exchange can be calculated from the enthalpy difference between the inlet and outlet of the distillate. EE can be calculated by the following equation [49]:

$$
E E=\frac{Q_{\text {diff }}}{Q_{T}}=\frac{Q_{\text {diff }}}{Q_{\text {diff }}+Q_{\text {cond }}}=\frac{J \cdot A \cdot H_{v}}{V_{p} \cdot \overline{C_{p}}\left(T_{p-\text { outlet }}-T_{p-\text { inlet }}\right)}
$$

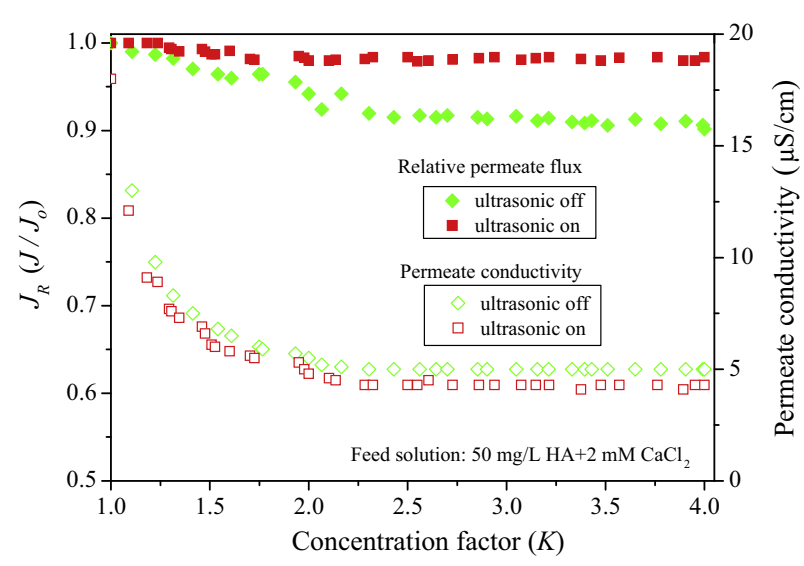

(a)

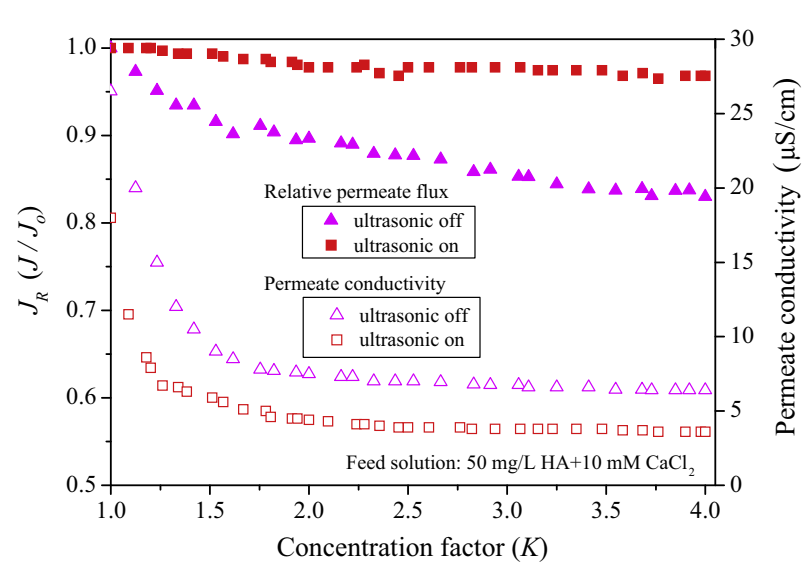

(b)

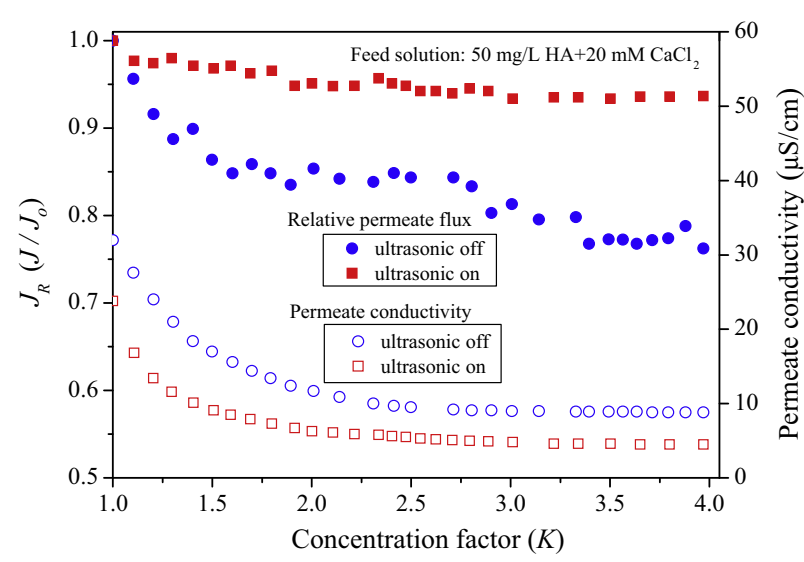

(c)

Fig. 12. Effect of ultrasound irradiation on the process of DCMD concentration of HA solution containing calcium ion: (a) $2 \mathrm{Mm} \mathrm{CaCl}_{2}$, (b) $10 \mathrm{Mm} \mathrm{CaCl}_{2}$, and (c) $20 \mathrm{Mm} \mathrm{CaCl}_{2}$. 

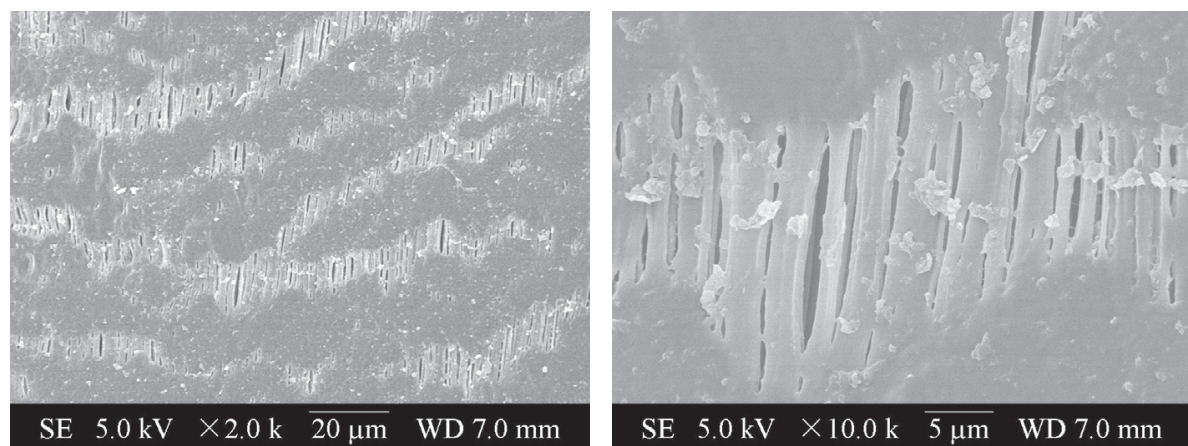

(a)
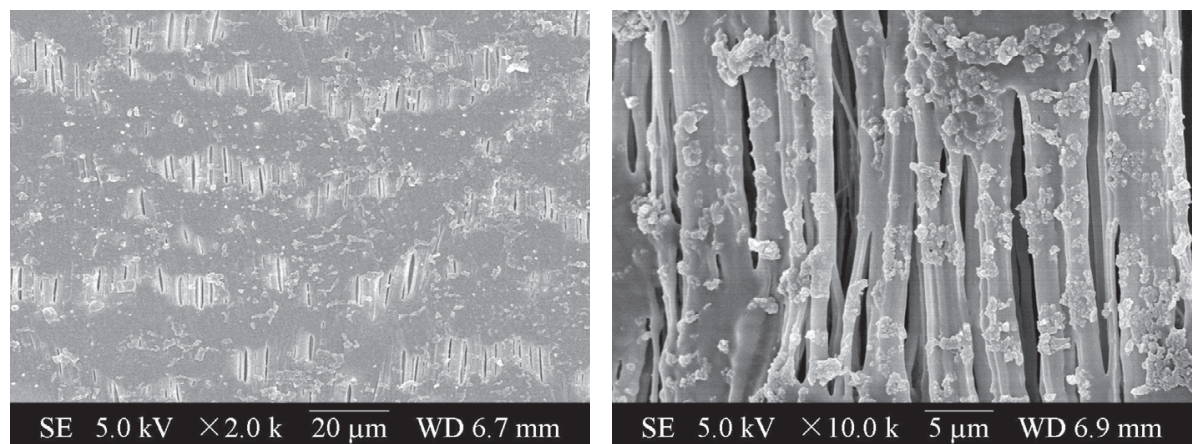

(b)
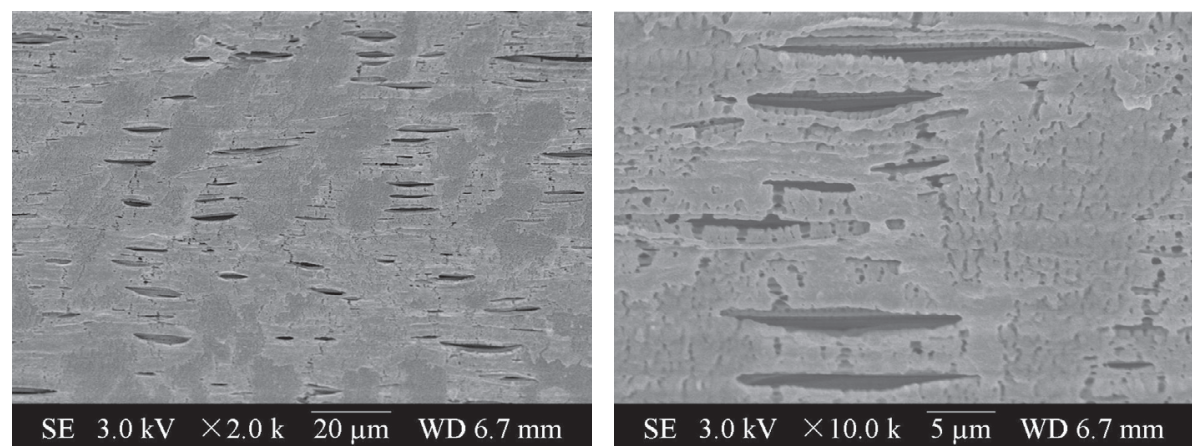

(c)

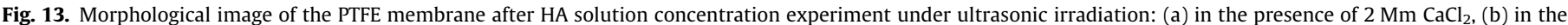
presence of $10 \mathrm{Mm} \mathrm{CaCl}_{2}$, and (c) in the presence of $20 \mathrm{Mm} \mathrm{CaCl}_{2}$.

where $A$ is the effective permeate area of the membrane module, $T_{p \text {-outlet }}$ is the cold distillate temperature at the outlet of membrane module. $\overline{C_{p}}$ is the average specific heat of water, which can be simplified as a constant value $4200 \mathrm{~J} /(\mathrm{kg} \mathrm{K}) . H_{v}$ is the latent heat of vaporization, in the range of temperature $273-373 \mathrm{~K}, H_{v}$ can be expressed as [50]:

$H_{v}=2024.3+1.7535 \cdot T$

where $T$ is the average temperature, and $T=\frac{T_{p-\text { inlet }}+T_{p-\text { outlet }}}{2}$, in $K$.

As shown in Fig. 11, the calculated thermal efficiency was around $12 \%$ for the DCMD process of pure HA solution, the EE value declined with the salt $\mathrm{CaCl}_{2}$ addition and the $E E$ value was less than $10 \%$ in the presence of $20 \mathrm{mM} \mathrm{CaCl}_{2}$. With the concentration factor increasing, the $E E$ value also decreased, and the $E E$ fell down to $7.5 \%$ at end of the concentration experiment in the presence of $20 \mathrm{mM} \mathrm{CaCl}$. According to Eq. (4), it can be clearly found that the high permeate flux meant higher $E E$ value and the latent heat of water evaporation became the main contribution to total heat transfer. As for the DCMD process with low permeate flux, the heat loss due to heat conduction across the membrane was the major contribution to total heat transfer and the $E E$ value became lower. The presence of divalent cation $\mathrm{Ca}^{2+}$ induced the $E E$ decrease may be attributed to two factors: the permeate flux decline and the thermal conductivity increase with the fouling layer formation.

\subsection{Ultrasonic irradiation effect on humic acid fouling mitigation}

To investigate the influence of ultrasonic irradiation on HA fouling in the presence of divalent cation $\mathrm{Ca}^{2+}$, DCMD concentration experiments were carried out with ultrasonic irradiation. The initial feed solution contained $50 \mathrm{mg} / \mathrm{L} \mathrm{HA}$ and the concentration of the salt $\mathrm{CaCl}_{2}$ in feed solution was varied in the range of 2-20 mM. Except for the additional ultrasonic irradiation, other operating parameters were in accordance with the previous experiments. The result of the mixed solution concentration through USDCMD is shown in Fig. 12.

The permeate flux increased markedly in the presence of ultrasonic irradiation as indicated in Fig. 12. The higher the concentra- 

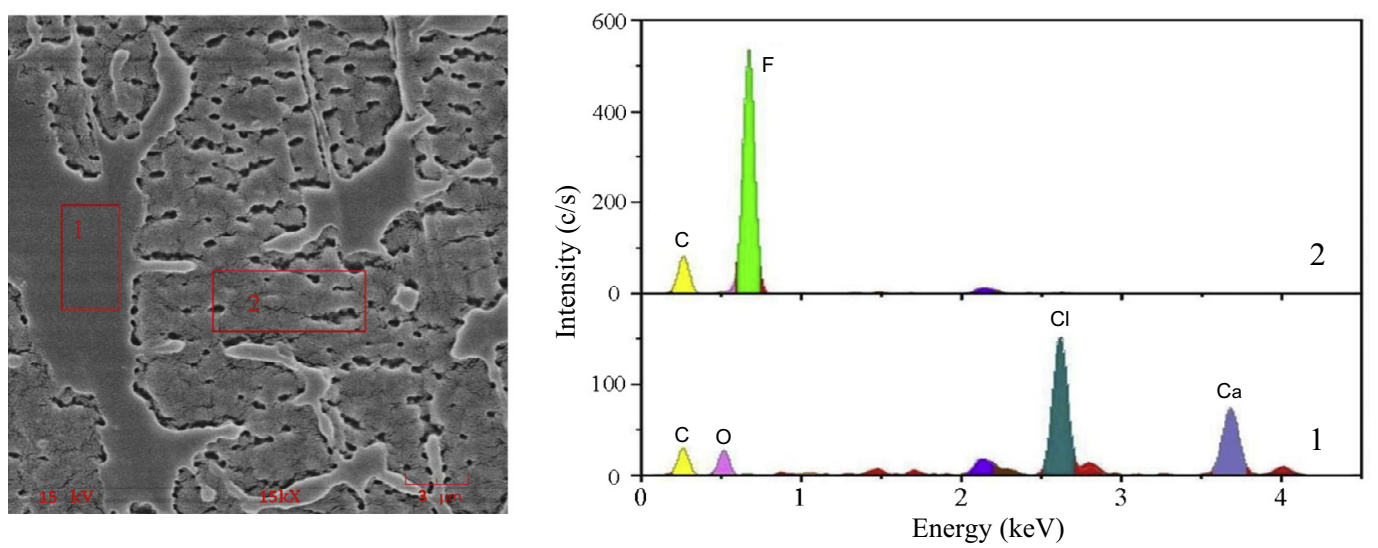

Fig. 14. SEM-EDS analysis of the fouling scattered on membrane surface in presence of ultrasonic irradiation. Feed solution: $50 \mathrm{mg} / \mathrm{L} \mathrm{HA}+20 \mathrm{mM} \mathrm{CaCl}$.

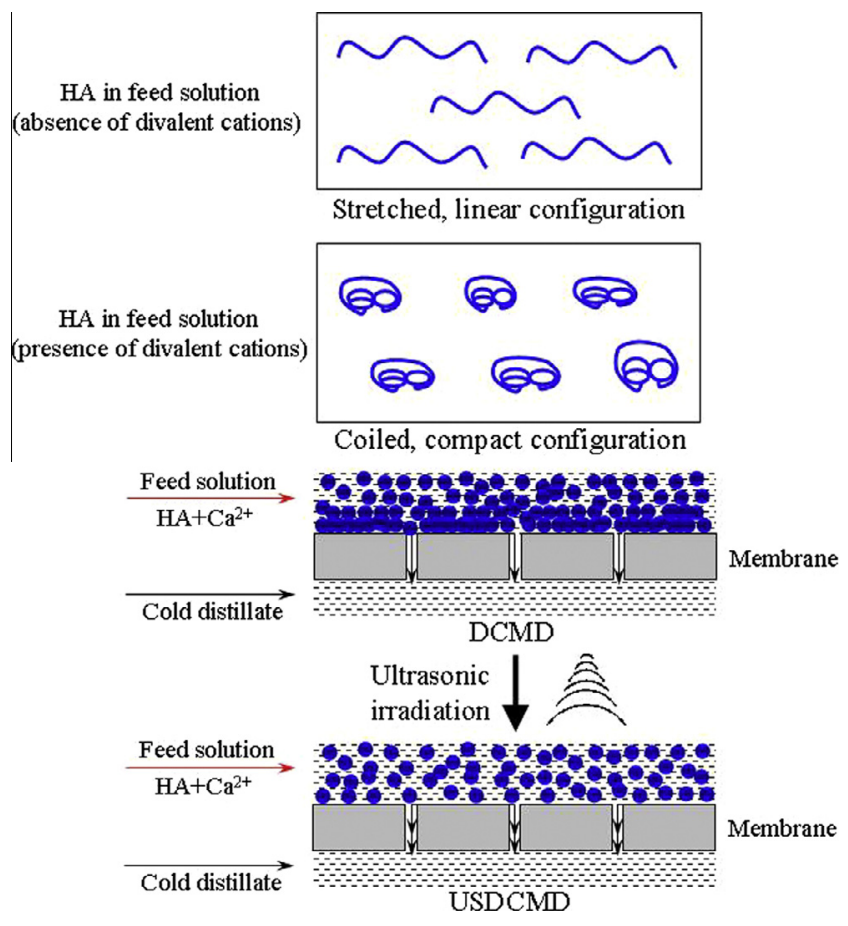

Fig. 15. Schematic illustration of ultrasonic irradiation effect on HA fouling mitigation.

tion of calcium ion in feed, the more obvious the ultrasonic enhancement of relative permeate flux could be obtained. It also can be found that the enhancement of relative permeate flux increased with concentration factor increasing. As can be seen from Fig. 12(c), in the presence of $20 \mathrm{mM} \mathrm{CaCl}_{2}$, the relative permeate flux maintained $94 \%$ when the concentration factor reached 4.0 with ultrasonic irradiation. In contrast, the relative permeate flux declined considerably in the absence of ultrasonic irradiation and the relative permeate flux went down to $76.3 \%$ when the concentration factor reached 4.0. The ultrasonic irradiation can effectively mitigate the HA fouling, which can be observed from the images of the membrane surface morphology. The difference between the surface morphologies of the membranes fouled with HA in the absence and presence of ultrasonic irradiation can be found by comparing Figs. 9 and 13. In the presence of ultrasonic irradiation, although there were some foulant aggregates scattered on the membrane surface, the membrane surface became much cleaner than that without ultrasonic irradiation. The most noticeable fouling mitigation effect was demonstrated in concentration process of the feed containing $20 \mathrm{mM} \mathrm{CaCl}_{2}$, there was no overall fouling layer covered on the membrane surface and the foulants were scattered and not as a whole when the experiment ended, it looked like that the hydrophobic membrane was still porous and most of the membrane pores kept open. The SEM-EDS analysis presented in Fig. 14 also demonstrated that it was possible a large part of the membrane surface maintained clean in the presence of ultrasonic irradiation.

The schematic illustration of the ultrasonic irradiation effect on mitigation of HA fouling during MD process was given in Fig. 15. Although the HA molecules in the feed solution became coiled and compact configuration from the stretched and linear configuration in presence of divalent cation $\mathrm{Ca}^{2+}[28]$ and the HA fouling was aggravated, ultrasonic irradiation could effectively mitigate membrane fouling caused by HA and prevented the permeate flux decline due to ultrasonic cleaning of the PTFE membrane surface. Ultrasonic wave can bring significant mechanical and thermal effects, and generated powerful shock wave and microstreaming with high speed. The mechanical effect promoted turbulence, reduced the boundary layer and intensified eddy diffusion. The microstreaming, shock wave and acoustic vortex streaming can continuously stimulate the liquid-membrane interface, therefore refreshed the interface and alleviated the deposition of HA aggregates. On the other side, due to ultrasonic irradiation, it became impossible to form an integral HA fouling layer covered the membrane surface, which was also beneficial to maintain permeate flux.

\section{Conclusions}

In the present work, an ultrasonic assisted direct contact membrane distillation hybrid process was designed and the influence of ultrasonic irradiation on HA membrane fouling mitigation during DCMD process was investigated.

Although the initial HA concentration did not affect permeate flux characteristics under experimental ranges, ultrasonic irradiation could enhance the permeate flux more than $30 \%$ without destroying HA rejection and all permeate HA concentration were below $0.40 \mathrm{mg} / \mathrm{L}$. It was also found that the higher the concentration factor was, the larger the ultrasonic enhancement of permeate flux could be obtained.

Severe permeate flux decline can be found when the salt $\mathrm{CaCl}_{2}$ was added into the HA solution. The presence of $\mathrm{Ca}^{2+}$ would aggravate HA organic fouling phenomenon via charge neutralization, complexation and formation of calcium bridges. Without liquid 
penetration into the membrane pores, the HA aggregates scattered on the membrane surface, and resulted in a thick and dense HA fouling layer. The fouling layer increased heat transfer resistance and reduced the pores available for water vaporization. As a result, both the permeate flux and thermal efficiency declined.

Ultrasonic wave can bring significant mechanical and thermal effects, and generated powerful shock wave and microstreaming with high speed. The mechanical effect promoted turbulence, reduced the boundary layer and intensified eddy diffusion. The microstreaming, shock wave and acoustic vortex streaming can continuously stimulate the liquid-membrane interface, therefore refreshed the interface and alleviated the deposition of HA aggregates. Under ultrasonic irradiation, although there were some HA fouling scattered on membrane surface, most of the membrane pores kept open and clean and the relative permeate flux can maintain about $94 \%$ when the concentration factor reached 4.0 .

\section{Acknowledgments}

Financial support provided by the National Natural Science Foundation of China (No. 51478454, 51138008) and the special fund from the State Key Laboratory of Environmental Aquatic Chemistry (No. 13Z04ESPCT) are gratefully acknowledged.

\section{References}

[1] K.Y. Wang, T.S. Chung, M. Gryta, Hydrophobic PVDF hollow fiber membranes with narrow pore size distribution and ultra-thin skin for the fresh wate production through membrane distillation, Chem. Eng. Sci. 63 (2008) 2587 2589.

[2] K.W. Lawson, D.R. Lloyd, Membrane distillation, J. Membr. Sci. 124 (1997) 125.

[3] A. Chafidz, S. Al-Zahrani, M.N. Al-Otaibi, C.F. Hoong, T.F. Lai, M. Prabu, Portable and integrated solar-driven desalination system using membrane distillation for arid remote areas in Saudi Arabia, Desalination 345 (2014) 36-49.

[4] C.R. Martinetti, A.E. Childress, T.Y. Cath, High recovery of concentrated RO brines using forward osmosis and membrane distillation, J. Membr. Sci. 331 (2009) 31-39.

[5] E. El-Zanati, K.M. El-Khatib, Integrated membrane-based desalination system, Desalination 205 (2007) 15-25.

[6] A. Alkhudhiri, N. Darwish, N. Hilal, Produced water treatment: application of air gap membrane distillation, Desalination 309 (2013) 46-51.

[7] F. Banat, S. Al-Asheh, M. Qtaishat, Treatment of waters colored with methylene blue dye by vacuum membrane distillation, Desalination 174 (2005) 87-96.

[8] M. Gryta, K. Karakulski, The application of membrane distillation for the concentration of oil-water emulsions, Desalination 121 (1999) 23-29.

[9] A. Criscuoli, J. Zhong, A. Figoli, M.C. Carnevale, R. Huang, E. Drioli, Treatment of dye solutions by vacuum membrane distillation, Water Res. 42 (2008) 5031 5037.

[10] P.P. Zolotarev, V.V. Ugrozov, I.B. Volkina, V.M. Nikulin, Treatment of waste water for removing heavy metals by membrane distillation, J. Hazard. Mater 37 (1994) 77-82.

[11] H.Y. Liu, J.L. Wang, Treatment of radioactive wastewater using direct contact membrane distillation, J. Hazard. Mater. 261 (2013) 307-315.

[12] M.M. Teoh, T.S. Chung, Membrane distillation with hydrophobic macrovoidfree PVDF-PTFE hollow fiber membranes, Sep. Purif. Technol. 66 (2009) 229 236.

[13] L.D. Tijing, Y.C. Woo, J.S. Choi, S. Lee, S.H. Kim, H.K. Shon, Fouling and its control in membrane distillation-a review, J. Membr. Sci. 475 (2015) 215-244.

[14] S. Shirazi, C.J. Lin, D. Chen, Inorganic fouling of pressure-driven membrane processes-a critical review, Desalination 250 (2010) 236-248.

[15] M.S. El-Bourawi, Z. Ding, R. Ma, M. Khayet, A framework for better understanding membrane distillation separation process, J. Membr. Sci. 285 (2006) 4-29.

[16] F. He, K.K. Sirkar, J. Gilron, Studies on scaling of membranes in desalination by direct contact membrane distillation: $\mathrm{CaCO}_{3}$ and mixed $\mathrm{CaCO}_{3} / \mathrm{CaSO}_{4}$ systems, Chem. Eng. Sci. 64 (2009) 1844-1859.

[17] L.D. Nghiem, T. Cath, A scaling mitigation approach during direct contact membrane distillation, Sep. Purif. Technol. 80 (2011) 315-322.

[18] M. Gryta, Fouling in direct contact membrane distillation, J. Membr. Sci. 325 (2008) 383-394.

[19] Y. Hao, A. Moriya, T. Maruyama, Y. Ohmukai, H. Matsuyama, Effect of meta ions on humic acid fouling of hollow fiber ultrafiltration membrane, J. Membr. Sci. 376 (2011) 247-253.

[20] D. Jermann, W. Pronk, S. Meylan, M. Boller, Interplay of different NOM fouling mechanisms during ultrafiltration for drinking water production, Water Res. 41 (2007) 1713-1722.
[21] W. Yuan, A.L. Zydney, Humic acid fouling during microfiltration, J. Membr. Sci. 157 (1999) 1-12.

[22] C. Jucker, M.M. Clark, Adsorption of aquatic humic substances on hydrophobic ultrafiltration membranes, J. Membr. Sci. 97 (1994) 37-52.

[23] M. Khayet, J.I. Mengual, Effect of salt concentration during the treatment of humic acid solutions by membrane distillation, Desalination 168 (2004) 373381.

[24] S. Srisurichan, R. Jiraratananon, A.G. Fane, Humic acid fouling in the membrane distillation process, Desalination 174 (2005) 63-72.

[25] G. Naidu, S. Jeong, S. Vigneswaran, Interaction of humic substances on fouling in membrane distillation for seawater desalination, Chem. Eng. J. 262 (2015) 946-957.

[26] S. Meng, Y. Ye, J. Mansouri, V. Chen, Fouling and crystallization behaviour of superhydrophobic nano-composite PVDF membranes in direct contact membrane distillation, J. Membr. Sci. 463 (2014) 102-112.

[27] D.M. Warsinger, J. Swaminathan, E. Guillen-Burrieza, H.A. Arafat, J.H. Lienhard $\mathrm{V}$, Scaling and fouling in membrane distillation for desalination applications: a review, Desalination 356 (2015) 294-313.

[28] S. Hong, M. Elimelech, Chemical and physical aspects of natural organic matter (NOM) fouling of nanofiltration membranes, J. Membr. Sci. 132 (1997) 159181.

[29] X. Jin, X.F. Huang, E.M.V. Hoek, Role of specific ion interactions in seawater RO membrane fouling by alginic acid, Environ. Sci. Technol. 43 (2009) 3580-3587.

[30] Q.F. Yang, Y.Q. Liu, Y.J. Li, Humic acid fouling mitigation by antiscalant in reverse osmosis system, Environ. Sci. Technol. 44 (2010) 5153-5158.

[31] L.Y. Liu, Z.W. Ding, L.J. Chang, R.Y. Ma, Z.R. Yang, Ultrasonic enhancement of membrane-based deoxygenation and simultaneous influence on polymeric hollow fiber membrane, Sep. Purif. Technol. 56 (2007) 133-142.

[32] R. Sanderson, J.X. Li, L.J. Koen, L. Lorenzen, Ultrasonic time-domain reflectometry as a non-destructive instrumental visualization technique to monitor inorganic fouling and cleaning on reverse osmosis membranes, J. Membr. Sci. 207 (2002) 105-117.

[33] J.X. Li, R.D. Sanderson, E.P. Jacobs, Ultrasonic cleaning of nylon microfiltration membranes fouled by Kraft paper mill effluent, J. Membr. Sci. 205 (2002) 247 257.

[34] A. Mirzaie, T. Mohammadi, Effect of ultrasonic waves on flux enhancement in microfiltration of milk, J. Food Eng. 108 (2012) 77-86.

[35] C. Zhua, G.L. Liu, C.S. Cheung, C.W. Leung, Z.C. Zhu, Ultrasonic stimulation on enhancement of air gap membrane distillation, J. Membr. Sci. 161 (1999) 8593.

[36] M. Cai, S.N. Zhao, H.H. Liang, Mechanisms for the enhancement of ultrafiltration and membrane cleaning by different ultrasonic frequencies, Desalination 263 (2010) 133-138.

[37] X.H. Li, J.X. Li, J. Wang, H. Wang, B.Q. He, H.W. Zhang, W.S. Guo, H.H. Ngo, Experimental investigation of local flux distribution and fouling behavior in double-end and dead-end submerged hollow fiber membrane modules, J. Membr. Sci. 453 (2014) 18-26.

[38] J.X. Li, R.D. Sanderson, In situ measurement of particle deposition and its removal in microfiltration by ultrasonic time-domain reflectometry, Desalination 146 (2002) 169-175.

[39] A.P. Mairal, A.R. Greenberg, W.B. Krantz, Investigation of membrane fouling and cleaning using ultrasonic time-domain reflectometry, Desalination 130 (2000) 45-60.

[40] T. Kobayashi, T. Kobayashi, Y. Hosaka, N. Fujii, Ultrasound-enhanced membrane-cleaning processes applied water treatments: influence of sonic frequency on filtration treatments, Ultrasonics 41 (2003) 185-190.

[41] S. Muthukumaran, S. Kentish, S. Lalchandani, M. Ashokkumar, R. Mawson, G. W. Stevens, F. Grieser, The optimisation of ultrasonic cleaning procedures for dairy fouled ultrafiltration membranes, Ultrason. Sonochem. 12 (2005) 29-35.

[42] M.L. Xu, X.H. Wen, X. Huang, Z.Y. Yu, M. Zhu, Mechanisms of membrane fouling controlled by online ultrasound in an anaerobic membrane bioreactor for digestion of waste activated sludge, J. Membr. Sci. 445 (2013) 119-126.

[43] M.L. Xu, X.H. Wen, Z.Y. Yu, Y.S. Li, X. Huang, A hybrid anaerobic membrane bioreactor coupled with online ultrasonic equipment for digestion of waste activated sludge, Biores. Technol. 102 (2011) 5617-5625.

[44] M.F.N. Secondes, V. Naddeo, V. Belgiorno, F. Ballesteros Jr., Removal of emerging contaminants by simultaneous application of membrane ultrafiltration, activated carbon adsorption, and ultrasound irradiation, J. Hazard. Mater. 264 (2014) 342-349.

[45] S. Muthukumaran, K. Yang, A. Seuren, S. Kentish, M. Ashokkumar, G.W. Stevens, F. Grieser, The use of ultrasonic cleaning for ultrafiltration membranes in the dairy industry, Sep. Purif. Technol. 39 (2004) 99-107.

[46] S.R. Gonzalez-Avila, F. Prabowo, A. Kumar, C.D. Ohl, Improved ultrasonic cleaning of membranes with tandem frequency excitation, J. Membr. Sci. 415416 (2012) 776-783.

[47] C. Loderer, D. Pawelka, W. Vatier, P. Hasal, W. Fuchs, Dynamic filtrationUltrasonic cleaning in a continuous operated filtration process under submerged conditions, Sep. Purif. Technol. 119 (2013) 72-81.

[48] M. Khayet, A. Velázquez, J.I. Mengual, Direct contact membrane distillation of humic acid solutions, J. Membr. Sci. 240 (2004) 123-128.

[49] K. Smolders, A.C.M. Franken, Terminology for membrane distillation, Desalination 72 (1989) 249-262.

[50] J. Phattaranawik, R. Jiraratananon, A.G. Fane, Heat transport and membrane distillation coefficients in direct contact membrane distillation, J. Membr. Sci. 212 (2003) 177-193. 